\title{
Exploration of the Countermeasures for the "Quick Protection" of Intellectual Property in the Pilot Free Trade Zone--Take Nanjing Area as a Case
}

\author{
Zhou Hua \\ School of Law, Jiangsu University, Zhenjiang, China
}

Email address:

3097383308@qq.com

To cite this article:

Zhou Hua. Exploration of the Countermeasures for the "Quick Protection" of Intellectual Property in the Pilot Free Trade Zone--Take Nanjing Area as a Case. International Journal of Law and Society. Vol. 4, No. 2, 2021, pp. 61-66. doi: 10.11648/j.ijls.20210402.11

Received: March 19, 2021; Accepted: March 30, 2021; Published: April 13, 2021

\begin{abstract}
The in-depth improvement of the quick protection of intellectual property rights in the pilot free trade zone is an inherent requirement for the further improvement of the intellectual property protection system in the pilot free trade zone in my country. At present, my country's pilot free trade zone has made some preliminary explorations in terms of rapid dispute resolution, efficient law enforcement, and rapid authorization. However, there are still some bottlenecks in the rapid protection of intellectual property rights in my country's pilot free trade zone, which are mainly reflected in the lack of professionalism in the intellectual property trial mechanism; the subject of multiple dispute resolution is not sound and lacks internal cohesive mechanisms; administrative law enforcement is not capable of resolving incidental civil disputes. In order to solve the above problems, It is necessary to categorize and set up secondary departments of my country's IP Tribunal to improve the trial mechanism according to the characteristics of intellectual property rights; improve the civil and social entities involved in the resolution of intellectual property disputes, and establish a linking mechanism for trial and other dispute resolution methods; strengthen the ability of administrative enforcement of intellectual property rights to resolve civil disputes.
\end{abstract}

Keywords: Intellectual Property Disputes Trial Mechanism, Multiple Dispute Resolution, Incidental Resolution of Civil Disputes

\section{Introduction}

The rapid protection of intellectual property rights is an important part of China's current policy of "strict protection, large protection, rapid protection, and simultaneous protection" of intellectual property rights. As the free trade zone is a highly open area, the protection of intellectual property rights is an unavoidable issue [1], especially the rapid protection of intellectual property rights. For example, the development strategy of the Jiangsu (Nanjing) Pilot Free Trade Zone requires exploring the systematization of intellectual property protection. Therefore, exploring the rapid protection of intellectual property rights in the Jiangsu (Nanjing) Pilot Free Trade Zone is of great significance to the research on intellectual property protection in my country, and is conducive to the innovation of the intellectual property protection system in the Pilot Free Trade Zone and the formation of reproducible experience.
The quick protection of intellectual property rights is to solve the efficiency problem of intellectual property protection, which mainly focuses on the quick confirmation and quick protection of intellectual property rights. In fact, it is the quick settlement of intellectual property disputes.

\section{2. "Quick Protection" of Intellectual Property Rights in the Pilot Free Trade Zone}

Exploring measures for the "fast protection" of intellectual property rights in the pilot free trade zone cannot be separated from the pilot free trade zone and the fast protection of intellectual property rights.

\subsection{Pilot Free Trade Zone}

The positioning of the nature of China's free trade zone is 
the prerequisite for determining the intellectual property protection measures in my country's pilot free trade zone. In terms of its nature, the China Pilot Free Trade Zone is a special zone between overseas areas and other non-free trade pilot zones in the country. Scholars call it an "enclave" in the image of scholars [2]. The definition of a pilot free trade zone usually includes "Areas outside the customs supervision of the national territory [3]" and "Domestic Customs Special Supervision Area [4]". The 1999 revised "Kyoto Convention" deleted from the definition the expression "exempt from customary customs supervision" for goods in pilot free trade zones stipulated in the 1973 Kyoto Convention F. 1 "Supplement to Free Zones". As a result, the "free zone is regarded as outside the customs border" is clearly limited to "in terms of import taxes and fees". In addition, the "customs" in "international customs and foreign customs" does not always refer to "customs borders", but also refers to the understanding of "tariffs" [5]. According to this understanding, the pilot free trade zone is still in my country's borders Inside, the customs law, intellectual property law and other legal systems still apply, but they are exempt from customs duties, but not from customs supervision [5].

Regarding the nature of my country's pilot free trade zone, the special features of the pilot free trade zone are far from being limited to the supervision of the customs. Even the administration and services of law enforcement, justice, etc. within the pilot free trade zone are different from those in the non-free trade pilot zone. And with the gradual opening of the free trade pilot zone in batches, its connotation and extension are not constant. In addition, the special features of the pilot free trade zone are not limited to customs. For example, in terms of intellectual property protection, the pilot free trade zone can carry out some exploration. Therefore, for the nature of my country's pilot free trade zone, it is essentially domestic, and the general provisions of domestic intellectual property protection are applicable to it. However, if special regulations are issued in the policy to allow them to explore freely, the special regulations shall be applied first. And its special features will be manifested differently in different periods. In the early days, because the free trade pilot zone and the "bonded zone" may overlap, their particularity is obvious in terms of tariffs. At present, in the "heat wave" of intellectual property protection, the special exploration in intellectual property protection is more obvious. Therefore, its connotation and extension are not rigid and fixed, but constantly enriched.

\section{2. "Quick Protection" of Intellectual Property}

The "fast protection" of intellectual property rights is a part of the systematic protection of intellectual property rights. From a macro level, the protection system of intellectual property rights includes strict protection, large protection, fast protection, and same protection. The systemization of intellectual property protection is a new requirement for intellectual property protection in my country in recent years. For example, in the construction requirements of the Jiangsu (Nanjing) Pilot Free Trade Zone established in 2019, it is necessary to realize the systematic construction of the protection and use of intellectual property rights. However, the systematization of the protection of intellectual property rights is not single-level, that is, not only a macro-level system is required, but also under this macro-level system, there are multiple micro-systems, and each micro-system must have its own system, needs to be continuously refined and nested. As for the research on the rapid protection of intellectual property rights, the current research is mainly limited to the external macro-system level [6]. Although it has explored its internal requirements, it is not a system. It is a scattered measure and has not formed a systematization of the meso level.

Regarding the definition of "quick protection" of intellectual property rights, Huang Hui and Zhai Pengwei believe that "quick protection is to maximize the efficiency of intellectual property protection, starting with the authorization, confirmation, and safeguarding of intellectual property rights, and optimize the protection procedures, thereby Promote the improvement of protection efficiency [6]". The rapid authorization of intellectual property rights refers to the rapid and efficient granting of rights to knowledge elements, mainly referring to patent rights, trademark rights, etc. Confirmation of intellectual property rights refers to the confirmation of ownership when there is a dispute over the ownership of intellectual property rights, confirming the authentic subject of the rights or determining whether the previous intellectual property rights holders can enjoy the intellectual property rights. The rapid protection of intellectual property rights refers to the quick relief of intellectual property rights after the intellectual property rights are infringed. Regarding the ways of protecting intellectual property rights, there are two general directions, one is to take the administrative way, and the other is to take the judicial way. In fact, the confirmation of intellectual property rights is often combined with the protection of intellectual property rights. In most disputes, the confirmation of rights is the prerequisite and the maintenance of the rights is the goal.

Efficiency is one of the value goals pursued by the "fast protection" of intellectual property rights. But in fact, since the rapid protection of intellectual property rights is a systematic project, efficiency is only its ultimate effect. To achieve the ultimate goal of efficiency, it needs "quick protection" to form a system. Therefore, the fast protection of intellectual property rights is actually a set of systematic projects in pursuit of the efficiency of intellectual property protection, which is bound to have the inherent requirements of systematization. Specifically, the "quick protection" of intellectual property rights in the Pilot Free Trade Zone has the following inherent requirements: First, comprehensiveness. The "quick protection" of intellectual property rights involves three aspects: rapid authorization, rapid determination and rapid protection of intellectual property rights. The protection of the entire process of an intellectual property right from its creation to its extinction. Second, multi-participation. fast protection of intellectual property rights require the joint efforts of multiple parties to achieve. Third, synergy. synergy is the proper meaning of the "fast protection" project of intellectual 
property rights.

\section{Exploring the "Quick Protection" of Intellectual Property in the Pilot Free Trade Zone--Taking the Nanjing Pilot Free Trade Zone as an Example}

\subsection{The Main Experience of the "Fast Protection" Mechanism in My Country's Pilot Free Trade Zone}

In order to understand the rapid protection of intellectual property rights in the pilot free trade zone, the official website of the free trade zone is searched and the way of actual visits is used to investigate the measures for the rapid protection of intellectual property rights in the pilot free trade zone, and the representative and common Sexual measures are formed in the following table.

And based on the existing universal practice, further study the bottleneck of the rapid protection of intellectual property rights in the pilot free trade zone.

\subsection{The Bottleneck of the "Fast Protection" of Intellectual Property Rights in the Free Trade Zone}

\subsubsection{The Intellectual Property Trial Mechanism Is Not Professional Enough}

The intellectual property trial mechanism is a key link in the quick confirmation and quick protection of intellectual property rights in the free trade pilot zone, and it is the main method and method of solving intellectual property disputes [7]. Therefore, the improvement of the trial mechanism for intellectual property cases in the Pilot Free Trade Zone is crucial to the realization of the "fast protection" of intellectual property rights. At present, in the rapid protection of intellectual property rights in my country's pilot free trade zones, the trial mechanism for intellectual property cases is not yet professional enough. Take the Jiangsu (Nanjing) Pilot Free Trade Zone as an example. The Jiangsu (Nanjing) Pilot Free Trade Zone is mainly concentrated in the Jiangbei New Area. The Jiangbei New Area has set up an intellectual property court for the trial of intellectual property cases, which is subordinate to the Nanjing Railway Transportation Court., is a dispatched court specializing in handling intellectual property cases in Jiangbei New Area. According to Su Gaofa [2020] No. 83, "Response of Jiangsu Higher People's Court on Approval of Non-technical Intellectual Property Cases in the People's Court of Nanjing Jiangbei New Area" District) In addition to patents, technical secrets, computer software, new plant varieties, integrated circuit layout designs, cases involving well-known trademark identification and monopoly disputes, general intellectual property civil cases and intellectual property administrative cases where the subject matter of litigation is less than 2 million yuan, Criminal case. In other words, the jurisdiction of technical intellectual property cases has not been delegated to the grassroots. According to the jurisdiction of the Nanjing Intermediate People's Court, the Nanjing Intermediate People's Court has jurisdiction over first-instance intellectual property civil cases under the jurisdiction of the Jiangsu Higher People's Court. In addition, patents, technical secrets, computer software, new plant varieties, integrated circuit fabrics in Nanjing, Zhenjiang, Yangzhou, Taizhou, Yancheng, Huai'an, Suqian, Xuzhou, and Lianyungang Graphic design, first-instance intellectual property civil cases involving well-known trademark identification and monopoly disputes. Therefore, technical intellectual property cases in the Nanjing Pilot Free Trade Zone are still under the jurisdiction of the Nanjing Intermediate People's Court. Specifically, the trial is conducted by the Nanjing Intellectual Property Court of the Nanjing Intermediate Court.

Table 1. Existing measures for quick confirmation and quick protection.

\begin{tabular}{ll}
\hline Typical measures & the main purpose \\
\hline Establish a free trade zone court or circuit court or intellectual property court (Shanghai Pilot Free & \\
Trade Zone, Jiangsu Nanjing Pilot Free Trade Zone, Guangzhou Hengqin Pilot Free Trade Zone, etc.); & \\
Establish arbitration courts, intellectual property arbitration mediation centers or introduce & Establish a diversified dispute resolution \\
international intellectual property international arbitration centers (Shanghai Pilot Free Trade Zone, & mechanism centered on trial. \\
Tianjin Pilot Free Trade Zone, Hainan Pilot Free Trade Zone, etc.); & $\begin{array}{l}\text { Unified and efficient local intellectual property right } \\
\text { Establish an intellectual property mediation center (Hubei Pilot Free Trade Zone, Shandong Pilot Free }\end{array}$ \\
$\begin{array}{l}\text { Trade Zone, Heilongjiang Pilot Free Trade Zone, etc.). } \\
\text { Establish a "three-in-one" law enforcement mechanism (Shanghai Pilot Free Trade Zone); } \\
\text { Build a unified administrative law enforcement system (Shanghai Pilot Free Trade Zone). }\end{array}$ & $\begin{array}{l}\text { Quick pre-examination of patent applications, } \\
\text { reexamination and invalidation requests, and patent } \\
\text { Establish intellectual property protection centers (Zhejiang Pilot Free Trade Zone, Tianjin Pilot Free }\end{array}$ \\
$\begin{array}{l}\text { Trade Zone, Shandong Pilot Free Trade Zone, etc.). } \\
\text { overseas guidance, etc. }\end{array}$ &
\end{tabular}

It can be seen that intellectual property disputes in technology-related cases closely related to the development of enterprises in the Nanjing Pilot Free Trade Zone are heard by the Nanjing Intellectual Property Court. However, compared with other cases, the trial mechanism of intellectual property cases is not professional enough [8]. Although a special intellectual property court has been set up for trial, intellectual property rights are treated separately. However, the position of handling intellectual property disputes in the entire adjudication system is still insufficient, and there is still a rough and marginal phenomenon. Combining the case characteristics of intellectual property cases and the establishment of intellectual property tribunals, it can be seen that the division of trial mechanisms is still not detailed 
enough to meet the requirements for rapid and efficient resolution of intellectual property disputes in the trial process. Intellectual property is a relatively macroscopic concept, which includes patents, trademarks, integrated circuit layout designs, new plant varieties, copyrights, etc. It can be divided into technical intellectual property and non-technical intellectual property rights from the perspective of whether there is a technical nature. Technical intellectual property rights mainly include computer software in copyright, patents, integrated circuit layout designs, new plant varieties, and typical biomedicine in patents. Most copyrights and trademarks, including design patents in patents, are generally non-technical intellectual property rights. Non-technical disputes in intellectual property rights cases are not technically strong, so they are more of a legal nature. Each type of technical intellectual property is highly specialized, and there are great differences between them. But simply set up an intellectual property tribunal to deal with all technical intellectual property rights, and simply mix different technical intellectual property rights in the intellectual property court, without considering the specialization and differentiation characteristics of technical intellectual property rights. The imperfection of the trial mechanism of intellectual property cases will also hinder the training of professional judges. Because the trials of intellectual property cases are not divided into categories, the judges have not formed a "professional" allocation, and the allocation of judges is unprofessional. It is difficult to realize the efficiency of the fast protection of intellectual property rights in the trial process.

\subsubsection{Insufficient Intellectual Property Dispute Resolution Mechanism}

Establishing and improving a set of trial-centered diversified dispute resolution mechanisms is the only way to realize the rapid protection of intellectual property rights in the pilot free trade zone. The settlement mechanism of multiple disputes is a very old topic in the field of general civil cases, and there are already relatively mature practices and mechanisms. However, in the field of intellectual property, multiple dispute resolution mechanisms have been advocated, but a relatively mature and complete mechanism has not been formed. Its imperfections are mainly reflected in two aspects:

First, the subject of multiple intellectual property dispute resolution is not "diversified", and the subject of dispute resolution is not sound. For the settlement of intellectual property disputes in my country's pilot free trade zone, the main practice in the past was to set up or introduce arbitration institutions and set up intellectual property mediation centers. However, these measures do not reflect the essence of the civicization and socialization of the multiple dispute resolution mechanism. Although the multiple dispute resolution mechanism seeks the participation of multiple parties in dispute resolution in form, it actually seeks to make full use of private and social resources to promote disputes. Harmonious and efficient solution. Simply relying on the ancient method of arbitration and setting up a special intellectual property mediation organization did not give full play to the advantages of social and non-governmental resources.

Second, the multiple dispute resolution mechanisms are not well connected [9]. In the multiple dispute resolution mechanism, trial is the core of the multiple dispute resolution mechanism. The reason why it is the core is that most cases are resolved by trial. The core reason is that trial is the state judicial organ, which is similar to other dispute resolution methods. In comparison, it has rigid binding force and enforceable power conferred by law, so it has more prestige. The advantage of other social dispute resolution mechanisms is that they are rich in social resources and can resolve intellectual property disputes in a decentralized manner. However, these social dispute resolution methods are flexible and generally have no enforcement power. Therefore, in the multiple dispute resolution mechanism, trial methods and other methods have their own advantages and disadvantages, and one of the key elements of a sound multiple dispute resolution mechanism is complementary advantages. However, the internal linkage mechanism of the multiple dispute resolution mechanisms in the current free trade zone is not yet perfect.

\subsubsection{Weak ability to Resolve Incidental Civil Disputes in Administrative Law Enforcement}

The settlement of intellectual property disputes in my country can also be resolved in the process of administrative law enforcement. After the reform of the local intellectual property system and mechanism in my country, the local city-level intellectual property offices merged into the General Administration of Market Supervision and Administration. Correspondingly, the enforcement of local intellectual property rights is also included under the Municipal Market Supervision Administration. According to the relevant laws and regulations of my country's intellectual property rights, in the process of local intellectual property law enforcement, in addition to penalizing administrative violations in accordance with law, law enforcement agencies can also mediate the civil legal relationship based on the application of the parties. However, after some intellectual property rights have been infringed, the right holder may not be able to meet the infringee's needs for rights relief after seeking administrative relief for the intellectual property rights. Instead, they may continue to seek judicial relief. When the judicial organs deal with civil disputes corresponding to similar administrative violations, they need to investigate the facts of the entire case. In this process, there is actually an overlap between administrative and judicial investigations of facts.

Regarding the situation that the parties continue to seek judicial relief after seeking the administrative agency to resolve the dispute, on the one hand, the ability of the administrative law enforcement link to resolve the corresponding civil disputes is relatively weak, and cannot fully meet the parties' needs for rights relief; on the other hand, due to the administrative The ability of law enforcement to resolve civil disputes has been relatively weak for a long time. Compared with the judicial remedy of the court, the right 
holders lacked less inner conviction, and the right holders have more confidence in judicial remedies. Therefore, the weak ability to resolve disputes in administrative law enforcement is one of the important reasons that hinder the rapid protection of intellectual property rights.

\subsection{Countermeasures and Suggestions to Improve the Rapid Protection of Intellectual Property Rights in Pilot Free Trade Zones}

\subsubsection{Further Professionalization of the Intellectual proPErty Trial Mechanism}

The establishment of a rapid intellectual property protection mechanism in the trial aspect requires the improvement of the intellectual property court trial mechanism as a breakthrough point, and different departments can be set up in accordance with the characteristics of intellectual property rights. Take the Nanjing Intellectual Property Court as an example. As the Nanjing Intermediate People's Court delegates non-technical small-amount intellectual property cases to the basic courts or dispatched courts, the establishment of the intellectual property courts of the intermediate people's courts can first treat intellectual property cases Divided into technical cases and non-technical cases where the target amount is not small, all non-technical cases are handled in the same secondary department.

Secondly, according to the different types of technical intellectual property rights, different secondary judicial departments are set up. In addition, technical cases should also be set in accordance with the growth trend of cases. For cases with obvious future growth trends, a separate secondary department can be set up, while for cases with a very small number of cases, it can be integrated into one department. Combined with the development of the intellectual property industry in the Nanjing Pilot Free Trade Zone, it can be seen that biomedicine and integrated circuits will be the dominant direction of the Nanjing Pilot Free Trade Zone in the future, so the development of the industry will inevitably lead to an increase in disputes of this type. Therefore, when setting up secondary courts within the intellectual property courts, independent secondary trial departments can be set up specifically for such cases, for example, typical technical knowledge such as integrated circuit layout design, biomedicine, computer software, new plant varieties, etc. can be separated into courts, while other atypical technical cases can be temporarily integrated in a comprehensive court for trial. This makes the setting of the intellectual property trial mechanism more in line with the characteristics of technological differentiation and specialization of intellectual property cases. Then, according to the professional needs of different secondary courts, the corresponding judges are allocated, and the work training of the judges is carried out according to the classification. Through the improvement of the trial mechanism, the adjudicators' ability to handle cases will be promoted, and then through the trial benefits of intellectual property cases, the rapid protection mechanism of intellectual property rights in trials will be improved.

\subsubsection{Improve Multiple Dispute Resolution and Mutual Cohesion Mechanisms}

In addition to judicial rulings, there are many ways to resolve intellectual property disputes. Moreover, judicial resources are scarce and should be placed on the settlement of key disputes. Therefore, it is necessary to improve the diversified system of intellectual property disputes and to deal with intellectual property disputes. In this process, we can give full play to the power of social and non-governmental organizations or institutions. British scholar McClay believes that "a kind heart is the best law." Although intellectual property disputes are inevitable, disputes can be resolved through the voluntary resolution of the parties or through the participation of a third party in mediation to reduce unnecessary litigation burden.

Therefore, in addition to perfecting arbitration and introducing arbitration institutions to resolve disputes [10], in particular, Through the triple construction of interim arbitration [11], the ad hoc arbitration system can improve the efficiency of arbitration [12]. Mediation institutions of intellectual property industry associations can be set up to mediate intellectual property disputes between enterprises, and the mediation role of law firms can also be used [13]. In addition, it is usually set up in my country's pilot free trade zones. There are intellectual property protection centers [14], and these intellectual property protection centers can also be endowed with mediation functions and play their role in dispute mediation. However, due to the lack of authority of such mediation channels and the formation of strong constraints, it often leads to the phenomenon of repeated parties before and after mediation, which in turn leads to mediation becoming "useless". Therefore, the court's mediation confirmation mechanism can be introduced, and the intellectual property court can confirm this type of soft mediation, and then endow it with enforceability and make up for its lack of rigid binding.

\subsubsection{Give Full Play to the Role of Administrative law Enforcement in the "Quick Protection" of Intellectual Property Rights in the Pilot Free Trade Zone}

Although the main purpose of administrative law enforcement is to investigate and deal with violations, administrative violation cases are often accompanied by civil disputes and civil compensation. In the process of investigating administrative cases, administrative law enforcement agencies will have a more comprehensive understanding of the entire case, including civil disputes. Therefore, it has the inherent advantages of incidental settlement of civil disputes in the corresponding case. If the administrative agency can efficiently resolve incidental civil cases in administrative law enforcement, on the one hand, certain judicial resources can be saved, on the other hand, disputes can be resolved quickly, administrative investigations and corresponding civil disputes can be resolved, and the parties' Litigation problems, because once intellectual property disputes enter the judicial process, the parties often have to pay high attorney fees and wait the long trial period. 
Therefore, local intellectual property administrative law enforcement should change its law enforcement thinking. It should not only pay attention to solving the problem of intellectual property administrative law enforcement, but also pay attention to the settlement of civil disputes accompanying the administrative law enforcement of intellectual property rights, and take advantage of the inherent advantages of understanding the case in the administrative law enforcement process, To help the parties resolve civil disputes, and strive to achieve the ideal state of administrative law enforcement and civil disputes resolved together. In addition, we must also pay attention to the connection between administration and justice to jointly promote the settlement of disputes [15].

\section{Conclusion}

The rapid protection of intellectual property rights in the pilot free trade zone is a systematic project, and quick confirmation and rapid rights protection are important aspects. In the process of promoting the rapid confirmation and rapid protection of intellectual property rights in the pilot free trade zone, it is necessary to improve the intellectual property trial mechanism and promote Judicial channels efficiently resolve intellectual property disputes. In addition, it is necessary to give full play to the application of multiple dispute resolution mechanisms in the field of intellectual property rights, as well as the ability of administrative entities to resolve civil disputes over intellectual property rights. Proceeding from multiple subjects, coordinated to promote the rapid protection of intellectual property rights in the pilot free trade zone.

\section{References}

[1] Xu Wenjin, Yao Jingyan. The Value Choice of Intellectual Property Protection in Shanghai Free Trade Zone_-From the perspective of judicial response to the parallel import of trademarks in the zone [J]. Journal of Shanghai University of Political Science and Law (Rules of Law), 2014, 29 (05): $77-82$.

[2] Song Hongsong. Intellectual Property Protection in the "Enclave" of Free Trade-The Dilemma and Countermeasures of Intellectual Property Law Enforcement in China Pilot Free Trade Zone [C]. China Intellectual Property Law Research Association. China Intellectual Property Law Research Association 2015 Annual Conference Paper Collection. China Intellectual Property Law Research Association: School of Intellectual Property, Renmin University of China, 2015: 1050-1058.

[3] Chen Hao. The construction of the special protection system of intellectual property rights in the China Pilot Free Trade Zone
[J]. Customs and Economics and Trade Research, 2017, 38 (04): 62-73.

[4] Yang Hong. Special Issues and System Improvement of Customs Enforcement of Intellectual Property Rights in Pilot Free Trade Zone [J]. Global Legal Review, 2019, 41 (02): 161-175.

[5] Wang Yafen, Wei Yu Village. Research on the peculiarity of intellectual property law enforcement in China Pilot Free Trade Zone [J]. The Rule of Law Research, 2020 (02): 44-57.

[6] Huang Hui, Zhai Pengwei. The challenges, ideas and countermeasures of intellectual property protection in China Pilot Free Trade Zone [J]. Social Scientist, 2019 (06): 122-129.

[7] Xia Hong, Han Tao. A review of the rule of law construction experience in my country's pilot free trade zone [J]. Journal of Liaoning Normal University (Social Science Edition), 2018, 41 (01): 50-58.

[8] Cui Wangwei. The construction of the judicial protection system of intellectual property rights in the free trade zone [J]. Forum on Science and Technology in China, 2015 (03): 130-134.

[9] Lu Mingyu, Jie Xiaoyu. Research on difficult issues of intellectual property protection in Henan Free Trade Zone [A]. Henan Law Society, Shanxi Law Society, Hubei Law Society, Anhui Law Society, Jiangxi Law Society, Hunan Province Law Society. The Twelfth "The Rise of Central China Rule of Law Forum" Paper Collection [C]. Henan Law Society, Shanxi Law Society, Hubei Law Society, Anhui Law Society, Jiangxi Law Society, Hunan Law Society: Henan Law Society, 2019: 12.

[10] Liu Tianzi, Chen Jie. Legal Thinking on Improving the Temporary Arbitration System in my country's Free Trade Zone [J]. Journal of Hebei University of Science and Technology (Social Science Edition), 2019, 19 (02): 62-68.

[11] Wang Chong. The way of constructing friendly arbitration rules in Qianhai Free Trade Zone: Theory and Three-tier Structure [J]. Hebei Law, 2019, 37 (04): 52-61.

[12] Zhang Jian. The legal construction of the provisional arbitration rules of China's free trade zone [J]. Journal of Shihezi University (Philosophy and Social Sciences Edition), 2017, 31 (05): 66-72.

[13] Li Lin. The lawyer mediation system in the dispute resolution mechanism of the free trade zone [J]. Journal of Henan Judicial Police Vocational College, 2019, 17 (04): 82-87.

[14] Chen Xinqi. China (Shantou) Intellectual Property Protection Center was approved for construction [J]. Chaoshang, 2020 (02): 13

[15] Cao Xiaolu, Wang Chongmin. Research on the Innovation of Intellectual Property Protection System of Free Trade Ports with Chinese Characteristics [J]. Administrative Management Reform, 2020 (08): 10-18. 